\title{
Design of New Polymers to Improve Radiation Stability of Plastic Scintillators
}

\author{
N. Barashkov, N. Korotkikh and T. Novikova \\ Karpov Institute of Physical Chemistry \\ Russia \\ F. Markley, A. Pla-Dalmau and G. Foster \\ Fermi National Accelerator Laboratory \\ P.O. Box 500, Batavia, Illinois 60510 \\ M. Rivard \\ University of Michigan \\ Ann Arbor, Michigan 48109.1200
}

November 1993 


\section{Disclaimer}

This report was prepared as an account of work sponsored by an agency of the United States Government. Neither the United States Government nor any agency thereof, nor any of their employees, makes any warranty, express or implied, or assumes any legal liability or responsibility for the accuracy, completeness, or usefulness of any information, apparatus, product, or process disclosed, or represents that its use would not infringe privately owned rights. Reference herein to any specific commercial product, process, or service by trade name, trademark, manufacturer, or otherwise, does not necessarily constitute or imply its endorsement, recommendation, or favoring by the United States Government or any agency thereof. The views and opinions of authors expressed herein do not necessarily state or reflect those of the United States Government or any agency thereof. 


\title{
DESIGN OF NEW POLYMERS TO IMPROVE RADIATION STABILITY OF PLASTIC SCINTILLATORS
}

\author{
N. BARASHKOV, N. KOROTKIKH and T. NOVIKOVA \\ Karpov Institute of Physical Chemistry \\ Russia
}

and

\author{
F. MARKLEY, A. PLA-DALMAU, and G. FOSTER \\ Fermi National Accelerator Laboratory* \\ Box 500 \\ Batavia, IL 60510
}

and

M. RIVARD

University of Michigan

Ann Arbor, MI 48109-1200

\begin{abstract}
Diffusion enhancers have been used to increase the radiation stability of scintillators. There is a danger that such additions will also allow the scintillation dyes to diffuse out of the matrix. Covalent bonding of the dyes into the matrix would eliminate any luminophore migration. We have demonstrated that dyes with vinyl and divinyl groups can be successfully bonded into a styrene matrix. Both primary and secondary luminophores have been bonded into the matrix and in several cases they have been compared with similar luminophores without the vinyl groups in otherwise identical compositions. In general the bonding does not greatly affect either the radiation stability of the composition or its light output, but is therefore proven to be an acceptable method of preventing luminophore migration. Scintillators with a base of aromatic or alicyclic epoxy resins have also been made with bonded luminophores. In these compositions the bonding is accomplished by using luminophores with one or two amine groups or epoxy groups. When using the amines, they are first prereacted with the epoxy resin and the modified epoxy is then cured with hexahydrophthalic anhydride or trimethoxyboroxine. The emission and absorption spectra of many of these reactive luminophores are given, along with the light outputs and radiation stability of the resulting scintilators.
\end{abstract}

Plastic scintillators are often used in high energy particle physics, especially as the sampling element in calorimeters. ${ }^{1}$ Modern colliding beam experiments

* Operated by the Universities Research Association, Inc., for the U.S. Department of Energy. 
subject scintillators to higher doses of radiation than ever before. Currently available plastic scintillators are susceptible to radiation damage and their light yield decreases with exposure time. A radiation hard plastic scintillator can be defined as a scintillator that can recover a substantial amount of its light output in a short time after being irradiated. In an attempt to accelerate the annealing period and reduce permanent damage, plasticizers have been added to the polymer base to enhance chain mobility. ${ }^{2}$ Unfortunately, this approach may give rise to a new drawback. The dopants may now also have higher mobility and diffuse out of the polymer matrix. In order to avoid this problem, the dopants could be covalently bound to the polymer matrix. ${ }^{3}$

The introduction of molecules of luminophores into polymer chains sometimes can increase resistance of luminophores ${ }^{4}$ or polymers 5 to ultra-violet light. Let us assume that the covalent bonding of luminophoric dopants with the polymer matrix of a scintillator can also increase its stability toward ionizing radiation. There are literature data 6,7 concerning the introduction of biphenyl, naphthalene and p-terphenyl into a polymer chain by copolymerization of their vinyl derivatives with styrene. The aforementioned authors observed some increase in radiation stability of copolymers of styrene or 2,4-dimethylstyrene with vinylbiphenyl in comparison with homopolymers which have no fragments of biphenyl.

An investigation of the radiation stability of scintillators with a matrix of copolymers of styrene and 12 different fluorescent compounds has been made. The fluorescent monomers contained one or two unsaturated groups, such as vinyl, methacryl, -allyl. The 4'-vinyl-9, 10-diphenylanthracene has been obtained from 9, 10-anthraquinone, phenylmagnesiumbromide and 4magnesiumbromstyrene. Methacryl- and allylderivatives of dyes have been obtained by treatment of aminoderivatives of dyes with chloranhydride methacrylic acid or allylchloride, respectively. Other new dyes have been synthesized by methods given in reference 3 .

In table 1 we give the chemical structure of the fluorescent monomers and the wavelengths of the maxima in their absorbance and fluorescence spectra in styrene solution. The spectral properties of most of these compounds make them suitable for use as secondary dopants in polystyrene scintillators. However, some of them, e.g. 4-vinyl-p-terphenyl, can be used as primary dopants.

In order to understand the influence of the covalent bonding of luminophoric dopants with polystyrene matrix, whenever possible we compared the transmittance and fluorescence spectra and the light yields of polystyrene scintillators with dopants of similar structure but without the presence of a vinyl group.

In table 2, the composition and characteristics of the resulting scintillators are shown. In these compositions p-terphenyl (PTP) or 2-(4-biphenylyl)-5-(4-tertbutylphenyl)- 1,3,4-oxadiazole (BPBD) are used as primary dopants. 


\section{TABLE 1}

\begin{tabular}{|c|c|c|c|c|}
\hline \multirow{2}{*}{ \# } & \multicolumn{2}{|l|}{ Luminophore } & \multirow{2}{*}{$\lambda_{\max }^{\mathrm{nm}}$} & \multirow{2}{*}{$\lambda_{\text {max }}^{\text {fluoresence }}$} \\
\hline & Structure & Name & & \\
\hline 1 & (O) $-\mathrm{CH}=\mathrm{CH}_{2}$ & VPT & 305 & 355,370 \\
\hline 2 & & A K K & 330,350 & 365,380 \\
\hline 3 & & VA & $350,375,390$ & 415,430 \\
\hline 4 & & VDPA & $355,375,390$ & 420,435 \\
\hline 5 & $\mathrm{OS}_{0}^{\mathrm{c}_{1} \mathrm{X}_{0}^{\mathrm{n}_{2}}}$ & Al-C-1 & 380 & 440 \\
\hline 6 & 10 & N-AI-C & 440,450 & 400,510 \\
\hline 7 & & Al-C-2 & 375 & 445 \\
\hline 8 & (잉요 & VPy & 325,340 & 320,240 \\
\hline 9 & $a=a+0<000$ & DMBO & 325,355 & 525 \\
\hline 10 & 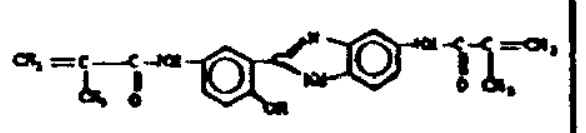 & DMBT & 320,350 & 510 \\
\hline 11 & 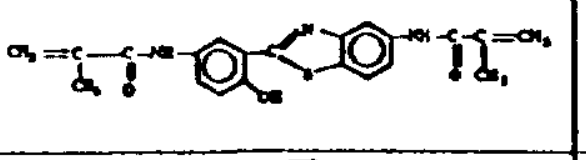 & DNBT & 330,370 & $\begin{array}{l}540 \\
\text { (Weak) }\end{array}$ \\
\hline 2 & $x=a-10)$ (0) & DMA & $355,370,385$ & 415,475 \\
\hline
\end{tabular}


Table 2

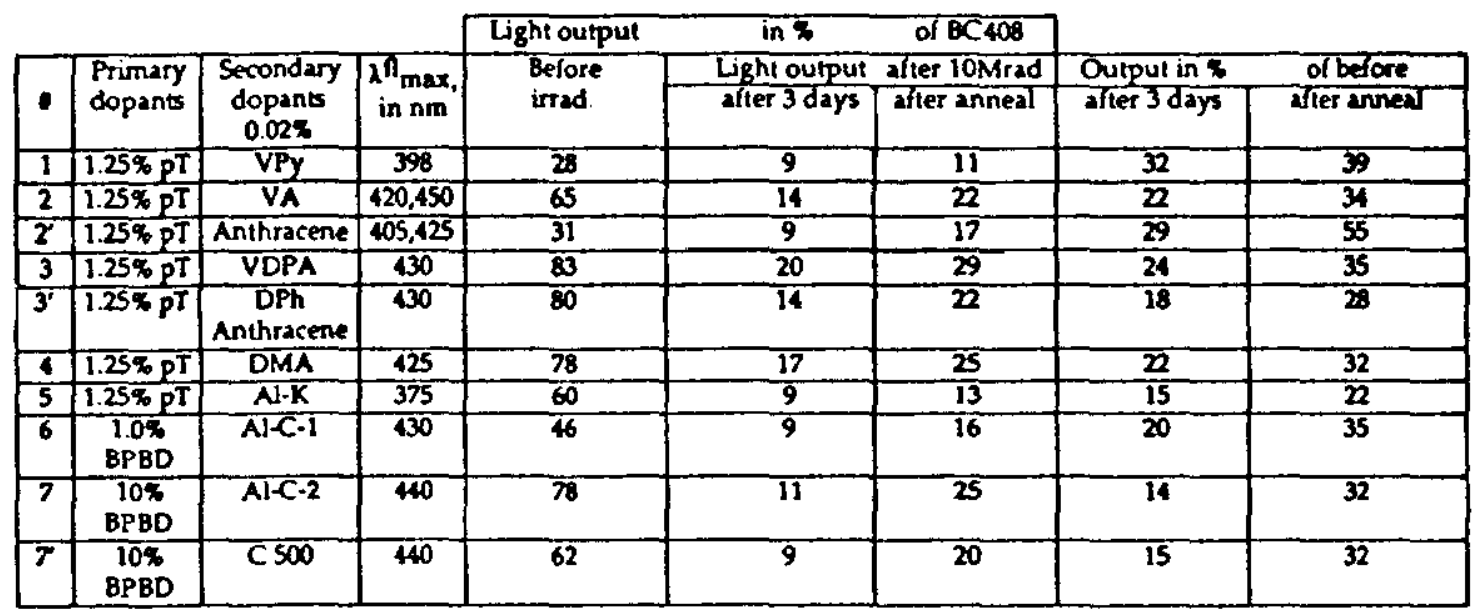

Comparing the two systems, we can see that the fluorescent properties and light output of each are similar before irradiation. The only exception is the copolymer of styrene with 9-vinylanthracene (\#2). Its light yield is twice as much as the light yield of the polystyrene scintillator with anthracene (\#2') as the secondary dopant. The increased fluorescence quantum yield of the 9-alkyl derivatives of anthracene in comparison with the yield of anthracene 7 is the explanation of this difference. It would have been better to have used 9-methylor 9-ethyl anthracene as secondary dopants for a more correct comparison.

A decrease of transmittance and light yield is observed after gammairradiation to $10 \mathrm{Mrad}$ in a nitrogen atmosphere. Immediately after irradiation, the light yield is one-third to one-sixth what it was before. After annealing in oxygen atmosphere (7 days, 160 psig) the light yield is one-half to one-fourth as much as it was before. If we compare bound and unbound luminophore systems using the data from the last 2 columns of table 2, we see that in the case of systems 2 and 2 ' the bound luminophore retains less of its light output after irradiation and annealing. In the case of systems 7 and $7^{\prime}$ the amount retained is about the same. In the case of systems 3 and $3^{\prime}$ the bound luminophore retains more of its light output.

Luminophoric dopants with two methacrylic groups are very interesting because these compounds can produce cross-linked copolymers after polymerization with styrene. The advantage of cross-linked copolymers is that they may make possible the use of large concentrations of diffusion enhancers. Such concentrations would otherwise cause a softening of linear polystyrene.

In table 3 are listed two dimethacrylic compounds and one methacrylamide compound with green fluorescence. Also shown are the fluorescence maxima, the relative brightness, and the decay time of copolymers of styrene with these luminophores. The brightness of the copolymers has been measured in 
Table 3

\begin{tabular}{|c|c|c|c|c|}
\hline : & $\begin{array}{l}\text { LUMENOPHYRE } \\
0.00 \%\end{array}$ & $\lambda_{\max }^{n m}$ & $\begin{array}{l}\text { Brightness } \\
\text { In \% of K-27 }\end{array}$ & $\begin{array}{l}\text { Decay } \\
\text { Time } \\
\text { ps }\end{array}$ \\
\hline 9 & $K \cdot 27$ & 495 & 100 & 11.8 \\
\hline 2 & DMBI & 500 & 38 & 5.2 \\
\hline 3 & DMBO & 530 & 44 & 5.4 \\
\hline 4 & NAC & 505 & 74 & 7.1 \\
\hline
\end{tabular}

comparison to the brightness of solid solutions of the dye K27 in polystyrene when illuminated by the light from scintillator SCSN38. In spite of lower brightness, these copolymers are interesting as green dopants for scintillator fibers. They have short decay times (5.2-7.1 ns compared to $11.8 \mathrm{n} \mathrm{sec}$ for K27), and big Stokes shifts $(150-170 \mathrm{~nm})$.

We have studied other scintillating compositions consisting of styrene copolymerized with $1 \%$ of reactive luminophores (see table 1 ) as primary dopants and $.02 \%$ of the non-reactive luminophores $\mathrm{BBQ}$ or $\mathrm{K} 27$ as secondary dopants. Table 4 shows the compositions and some properties of these scintillators.

TABLE 4

Light Output Measurements of Copolymers of Styrene and Vinyluminophores

\begin{tabular}{|c|c|c|c|c|c|c|c|c|}
\hline & & & & & son or & $\operatorname{loc}$ in $x$ & $\| \mathbb{C}$ & \\
\hline & Doparm & & & & arear h & cotioton & $m A$ & החות \\
\hline & & & $n \operatorname{nm}$ & $\infty$ & $\min ^{\infty}$ & n. & $\therefore$ & $\infty$ \\
\hline 1 & Vyy & Beo & 405,400 & 21 & 6.5 & 7 & - & 12 \\
\hline 2 & VA & K27 & $430,470,495$ & 10 & 4.6 & 5.3 & 6.8 & 11 \\
\hline 2 & Antheranese & K27 & $410,470,495$ & 15 & 5.6 & 6.3 & 75 & 10 \\
\hline 3 & VOPA & K27 & $440,470,495$ & 36 & 11 & 12 & 17 & 2 \\
\hline 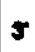 & Diphenylar & K27 & $430,470,495$ & 30 & 14 & 17 & 2 & 20 \\
\hline 4 & DMA* & K27 & $435,470,490$ & 30 & 23 & 33 & 68 & 68 \\
\hline s & NK & 890 & 380.490 & 30 & e & 10 & 13 & 17 \\
\hline - & $N \cdot C_{-2}$ & K27 & $435,460,495$ & 24 & 2.8 & 3.1 & 5.3 & 5.3 \\
\hline 6 & C s00 & K27 & 460,495 & 25 & 1.8 & 2.3 & 2.3 & 7.8 \\
\hline
\end{tabular}

- Concentrafion ol DMA $=.5 *$ 
As we did with the systems in table 2, we have compared the light output before and after irradiation of scintillators based on copolymers of styrene and reactive primary dopants with the light output of scintillators based on solid solutions in polystyrene of dopants of similar structure. We have obtained the best light output before irradiation ( $38 \%$ of $\mathrm{BC} 408$ ) and the best light output after irradiation and 33 days annealing ( $76 \%$ of the before irradiation measurement) for the composition with diphenylanthracene as the primary dopant. By comparing the data from sample 2 with 2', and sample 3 with $3^{\prime}$, and sample 6 with 6 ', we conclude that the covalent bonding of the primary dopants with the polymer matrix does not increase the light output. The data show that it might cause a slight decrease in the light output retained after irradiation and annealing. Note that the data for bound secondary dopants showed mixed results.

Since no large deleterious effects were seen with either bound primary or secondary dopants we can conclude that these reactive luminophores are suitable for use in diffusion enhanced systems where unbound luminophores might migrate out of the base plastic.

We have also investigated new polymer base epoxy resins and new fluorescent compounds containing functional groups which are able to react with these resins. Dyes with one or two glycidyl groups have been synthesized by treatment of hydroxy- or aminoderivatives of dyes with epichlorhydrin by the method of reference 3. An epoxy system has the advantage of yielding polymers of various chemical structures just by changing the epoxy monomers and curing agents. Moreover epoxy polymers are highly crosslinked networks. This characteristic may facilitate the use of larger amounts of diffusion enhancers without making the scintillator too soft.

Two types of epoxy resins have been used. One with an aromatic structure, the diglycidylether of bisphenol-A (DER 332), and one with cycloaliphatic structure, (ERL-4234). Scintillators were made by dissolving luminophores having one or two glycidyl groups (see table 5) in the epoxy resins and curing with trimethoxyboroxine or hexahydrophthalic anhydride (HHPA). After curing, the luminophoric dopants should be covalently bound to the polymer matrix. The epoxy-epoxy reaction catalyzed by trimethoxyboroxine (TMBOX) produces more nearly colorless polymers.

A second method of introducing molecules of luminophores into polymer chains is to prereact epoxy resin with diaminoluminophores (table 5) by heating the mixture overnight at $110-120^{\circ} \mathrm{C}$. From this process slightly yellow olygomers are usually obtained. Subsequently these olygomers are reacted with TMBOX (overnight at $\left.90^{\circ} \mathrm{C}\right)$ or with HHPA $\left(5-20\right.$ days at $\left.90^{\circ} \mathrm{C}\right)$. We have found that the reaction of epoxy groups with HHPA may be accelerated by benzimidazole derivatives used as secondary dopants (samples 3,4,11 in table 5).

Also in table 5 the composition and some properties of the resultant scintillators are shown. These scintillators contain $1.5 \%$ p-terphenyl as primary 


\section{TABLE 5}

\begin{tabular}{|c|c|c|c|c|}
\hline \# & $\begin{array}{c}\text { Secondary Dopant } \\
.02 \%\end{array}$ & $\begin{array}{l}\text { Curing } \\
\text { Agent }\end{array}$ & $\lambda_{\max }^{n} \mathrm{~nm}$ & $\begin{array}{l}\text { Llght Output } \\
\text { in } \% \text { of } \\
\text { BC } 408\end{array}$ \\
\hline 1 & n-(0) & TMBOX & 470 & 37 \\
\hline 2 & -6 & HHPA & 460 & 14 \\
\hline 3 & & TMBOX & 450 & 28 \\
\hline 4 & & HHPA & 450 & 17 \\
\hline 5 & DPH Anthracene & TMBOX & 420,440 & 40 \\
\hline 6 & 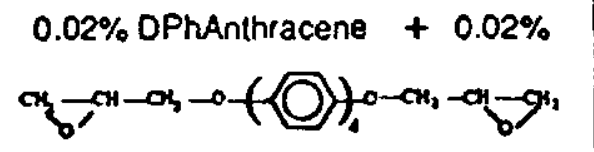 & TMBOX & $\begin{array}{c}380 \text { ( shoulder) } \\
420,440\end{array}$ & 54 \\
\hline 7 & & TMBOX & 405 ( shoulder) & 28 \\
\hline 8 & 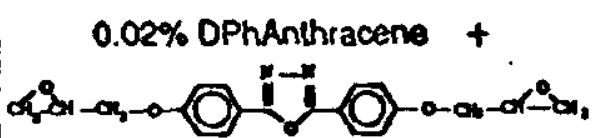 & TMBOX & $\begin{array}{c}390 \text { ( shoulder) } \\
420,440\end{array}$ & 51 \\
\hline 9 & & TMBOX & $\begin{array}{c}380 \text { ( shoulder) } \\
470\end{array}$ & 43 \\
\hline 10 & & TMBOX & 405,430 & 34 \\
\hline 11 & & HHPA & 455 & 14 \\
\hline \multicolumn{5}{|c|}{ Epoxy Resin } \\
\hline & y Dopant $1.5 \%$ pT & & & \\
\hline
\end{tabular}


dopant and $0.02 \%$ diamino- or diglycidyl luminophores as secondary dopants. In some cases we used two luminophores as secondary dopants. Diglycidyl ethers of dihydroxyquaterphenyl or dihydroxydiphenyloxadiazole efficiently absorb the emission of the primary dopant and fluoresce in the region of absorption of the secondary luminophores. Usually the light yield of epoxy polymer scintillators with two secondary dopants is higher than the light yield of scintillators with one secondary dopant of the same chemical structure as one of the two (compare the characteristics of samples 6,8 ,and 9 with those of samples 1 and 5 in table 5).

If we compare properties of copolymers with fragments of diaminoluminophores prepared by curing with TMBOX, with properties of copolymers prepared by curing with HHPA, we see that the light yield of the first type is higher than that of the second type, as table 5 shows.

The highest light yield (54\% in comparison with BC408, sample 3) was obtained from the diglycidyl ether of bisphenol A using TMBOX as curing agent, PTP as primary dopant, and a diglycidyl derivative of quaterphenyl and diphenylanthracene as secondary dopants. Epoxy systems with light yields of $70 \%$ of $\mathrm{BC} 408$ have been reported.2

The epoxy polymers obtained from cycloaliphatic epoxy resins alone can not be used as scintillators because they have no aromatic links. To make scintillators from these epoxy polymers it is necessary to add large concentrations of naphthalene or other aromatic compounds.

Table 6 gives the composition and some characteristics of scintillators obtained from cycloaliphatic resins. HHPA as curing agent and $5-15 \%$ of naphthalene have been used in the preparation of these epoxy scintillators. Table 6 shows that the light yield of these epoxy scintillators is lower than the light yield of epoxy scintillators obtained from aromatic epoxy resins (table 5). We hope that the light yield of scintillators obtained from cycloaliphatic epoxy resins can be increased by increasing the concentration of naphthalene.

Two types of new scintillators obtained from modification of polystyrene and from epoxy polymers have been investigated in this work. The absorption, fluorescence and scintillation light yield characteristics before and after irradiation have been determined.

\section{Acknowledgments}

We would like to acknowledge the assistance of $\mathrm{H}$. Gustfason of the University of Michigan and R. Blackburn at the Phoenix Memorial Reactor where the irradiations were done. This work as presented was performed in part at Fermi National Accelerator Laboratory, which is operated by Universities Research Association, Inc. under contract with the U.S. Department of Energy. 


\section{TABLE 6}

\begin{tabular}{|c|c|c|c|c|}
\hline \# & $\begin{array}{c}\text { Primary } \\
\text { Dopant }\end{array}$ & $\begin{array}{c}\text { Secondary Dopant, } \\
0.02 \%\end{array}$ & $\lambda_{\max }^{n}$ & $\begin{array}{l}\text { Light } \\
\text { Output } \\
\text { in o\% of } \\
B C 408\end{array}$ \\
\hline 1 & $\begin{array}{l}1.5 \% \mathrm{p}^{\top} \\
5 \% \mathrm{~N}^{*}\end{array}$ & $\begin{array}{l}\text { Tetraphenylbutadiene } \\
\text { (TPhB) }\end{array}$ & 430 & 9 \\
\hline 2 & $\begin{array}{l}1.5 \% \mathrm{p}^{\top} \\
5 \% \mathrm{~N}^{*}\end{array}$ & (O) & $\begin{array}{l}360 \dagger \\
430\end{array}$ & 13 \\
\hline 3 & ${ }_{10 \%}^{1.5 \%} \mathrm{p}^{\top}$ & $0.02 \%$ TPhB & $\begin{array}{l}370 \dagger \\
430\end{array}$ & 11 \\
\hline 4 & $5 \% \mathrm{pT}$ & DPh Anthracene & 420,440 & 9 \\
\hline 5 & $5 \% \mathrm{pT}$ & 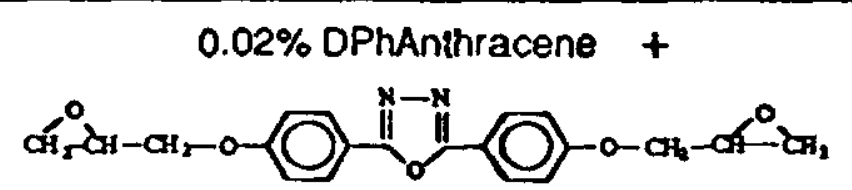 & $\begin{aligned} 360 t \\
420,440\end{aligned}$ & 9 \\
\hline 6 & ${ }_{15 \%}^{1.5 \%} \mathrm{P}^{\top}$ & 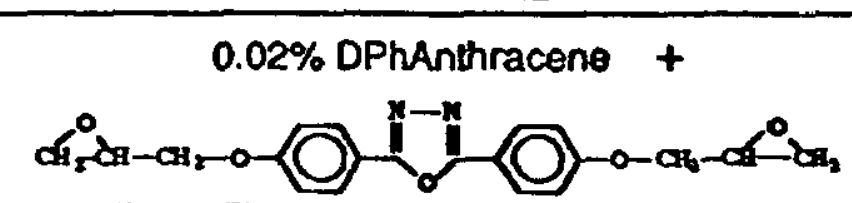 & $\begin{aligned} 360 t \\
420,440\end{aligned}$ & 13 \\
\hline 7 & $\begin{array}{l}1.5 \% \mathrm{pT}^{\top} \\
5 \% \mathrm{~N}^{*}\end{array}$ & 0.02\% DPAAntracene + & $\begin{aligned} 360 t \\
420,440\end{aligned}$ & 11 \\
\hline 8 & $1.5 \% \mathrm{pT}$ & $\left.\mathrm{CH}_{2}-\mathrm{CH}_{1}-\mathrm{CH}_{2}-\mathrm{O}(\mathrm{O})\right)_{1} \mathrm{O}_{1}-\mathrm{CH}_{2}-\mathrm{OA}_{\mathrm{O}}-\mathrm{O}^{\mathrm{H}_{2}}$ & $380 t$ & 6 \\
\hline 9 & $\begin{array}{l}1.5 \% \mathrm{P}^{\top} \\
10 \% \mathrm{~N}^{*}\end{array}$ & $\mathrm{H}_{2} \mathrm{~N}-\mathrm{O}$ & 440 & 11 \\
\hline 10 & $\begin{array}{l}1.5 \% \mathrm{pT}^{\top} \\
5 \% \mathrm{~N}^{*}\end{array}$ & (0) & $405 t$ & 9 \\
\hline
\end{tabular}

* = Napthylene

$t=$ shoulder
Curing Agent HHPA s $\int_{0}^{9}$

$\underset{\text { ERL }}{\text { Epoxy Resin }} \mathrm{Q} s$

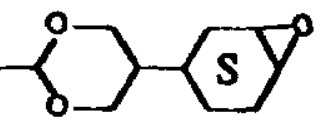




\section{References}

1. D. Green, Radiat. Phys. Chem., V41 (1993) N 1/2, p. 19-30

2. F. Markley, D. Woods, A. Pla-Dalmau, Radiat. Phys. Chem,. V41, (1993) BN 1/2, p. 135-152.

3. N. Barashkov, O. Gunder, Fluorescent Polymers, (Ellis Harwood, 1993).

4. V. Ivanov, N. Barashkov, V. Selikhov and al., Polym. Degr. and Stab., V35, (1992) p.267-270.

5. Y. Yakovlev, R. Nurmuchametov, N. Barashkov and al., Polym. Degr. and Stab., V37, (1992) p. 115-124.

6. Gunder, O.A., Radiation Stability of Plastic Scintillators, Preprint ISC-91-15. Kharkov: Institute for Single Crystals, (1991), p. 19.

7. Gunder, O.A., V.S. Koba, Radiokimiya, V11, (1969) N 1, p. 119-122.

8. I. Berlman, The Handbook of Fluorescent Spectra of Aromatic Molecules, Academic Press., NY., (1971). 